\title{
Forkhead-box A1 induces cell senescence in endometrial cancer by regulating $\mathrm{p}^{\mathrm{INK4a}}$
}

\author{
JINGYUN WANG $^{1}$, YIDING BIAN ${ }^{1}$, YUN LIAO $^{2}$, YE XIA $^{1}$ and XIAOPING WAN ${ }^{1}$ \\ ${ }^{1}$ Department of Obstetrics and Gynecology, Shanghai First Maternity and Infant Hospital, Tongji University \\ School of Medicine, Shanghai 201204; ${ }^{2}$ Department of Obstetrics and Gynecology, Women's Hospital, \\ School of Medicine, Zhejiang University, Hangzhou, Zhejiang 310006, P.R. China
}

Received January 31, 2016; Accepted March 15, 2016

DOI: $10.3892 /$ or.2016.4907

\begin{abstract}
We previously identified FOXA1 as a tumorsuppressor in EC cells. In the present study, we sought to delineate the different roles of FOXA1 associated with cell senescence and further investigated the correlation between FOXA1 and p16 ${ }^{\mathrm{INK} 4 \mathrm{a}}$ in the progression of EC. Using reverse transcription-quantitative PCR (RT-qPCR), we found that FOXA1 expression was significantly downregulated in EC cells compared to that in normal endometrial cells. Functionally, senescence-associated $\beta$-galactosidase staining, 3-(4,5-dimethylthiazol-2-yl)-2,5-diphenyltetrazolium bromide (MTT), clonogenic and Transwell assays showed that in addition to acting as a pioneer factor, FOXA1 was significantly upregulated in senescent EC cells. Furthermore, restoration of FOXA1 expression triggered multiple steps of cellular senescence in EC cells and activated p16 ${ }^{\mathrm{INK} 4 \mathrm{a}}$ expression. All of these findings indicate that FOXA1 promotes cell senescence in EC by interaction with $\mathrm{p} 16^{\mathrm{INK} 4 \mathrm{a}}$, possibly via the AKT pathway. Notably, a selective PI3K inhibitor raised the possibility that FOXA1-induced senescence is associated with the AKT pathway in EC cells. Collectively, the present study provides a conceivable molecular mechanism by which cell senescence acts as the barrier to EC, and is regulated by FOXA1-induced p16 ${ }^{\text {INK4a }}$ expression. This may be a newly identified regulatory mechanism of cell senescence in EC.
\end{abstract}

\section{Introduction}

Endometrial cancer (EC) is one of the most common cancers worldwide. In 2015, in the US alone, 54,870 women

Correspondence to: Professor Xiaoping Wan, Department of Obstetrics and Gynecology, Shanghai First Maternity and Infant Hospital, Tongji University, School of Medicine, 2699 Gaokexi Road, Shanghai 201204, P.R. China

E-mail: wanxiaoping@tongji.edu.cn

Abbreviations: EC, endometrial cancer; FOXA1, forkhead-box A1

Key words: endometrial cancer, forkhead-box A1, cell senescence, p16 ${ }^{\text {INK4a }}$ were newly diagnosed with $\mathrm{EC}$ and 10,170 may die of this disease (1). Hysterectomy with or without adjuvant whole pelvic radiation is the standard treatment; however, $30 \%$ of EC cases are not diagnosed until regional or distant metastasis has developed, resulting in a poorer outcome (2). Therefore, identification of additional molecular mechanisms associated with tumorigenesis and progression of EC, and the discovery of novel diagnostic and prognostic markers for EC are critical for making informed treatment decisions.

Forkhead-box A1 (FOXA1) is a member of the FOX family of transcription factors, which are involved in carcinogenesis as oncogenes and/or tumor-suppressor genes (3). We have previously shown that FOXA1 is a tumor-suppressor in EC, although the mechanism by which FOXA1 affects the progression of EC is incompletely understood (4).

Cell senescence is characterized by a series of distinctive phenotypes and biomarkers, such as large and flattened morphology, increased senescence-associated $\beta$-galactosidase activity (SABG), accumulation of senescence-associated heterochromatic foci (SAHF) and permanent G1 phase arrest (5). Cell senescence is the result of telomere shortening and damage accumulation, which have both anti-oncogenic and pro-oncogenic effects (6), and is a beneficial compensatory response to damage, representing a potent tumor-suppressor mechanism (7). In contrast, there is also increasing evidence that the incidence of cancer increases with age, indicating that the senescence of non-cancerous cells in aging tissues may exert pro-carcinogenic effects.

p16 $6^{\text {INK4a }}$ is a tumor-suppressor protein that functions as an inhibitor of cyclin-dependent kinase (CDK)4/6. As a key regulator of G1 phase cell cycle arrest and senescence, p16 on chromosome $9 \mathrm{p} 21$ is inactivated in a wide range of human cancers $(8,9)$. In view of the pivotal role of $\mathrm{p}^{16^{\mathrm{INK} 4 \mathrm{a}} \text { in both tumor }}$ suppression and cell senescence, numerous investigations have been conducted to elucidate the genetic or epigenetic mechanisms regulating its activation in senescence or its inactivation in carcinogenesis. It has been reported that in senescence, FOXA1 binds to the promoter region of p16, stimulates chromatin remodeling and enables long-range promoter-enhancer communication to promote p16 expression (10).

Alterations in DNA methylation, chromatin structure, histone modifications, and epigenetic regulatory mechanisms are critical hallmarks of both senescence and cancer $(7,11)$. 
Given by the close association between senescence and tumors (12), we focused on the role of FOXA1 in EC in the present study. Our results provide further support to the mounting evidence showing that FOXA1 is a favorable prognostic marker in EC and mediates p16 ${ }^{\mathrm{INK} 4 \mathrm{a}}$ activation to promote cell senescence.

\section{Materials and methods}

Patients and tissues. Tissues samples for immunohistochemistry (IHC) were obtained from 61 patients with EC and 15 patients with normal endometrium who underwent hysterectomy as treatment for other diseases such as adenomyosis or myoma at the Shanghai First Maternity and Infant Hospital, Tongji University School of Medicine from 2013 to 2015. Primary fresh tissues were obtained from patients immediately after surgical removal and were snap-frozen in liquid nitrogen for storage prior to further use. The IHC protocol was performed as previously described (4).

The present study was approved by the Human Investigation Ethics Committee of Shanghai First Maternity and Infant Hospital, Tongji University School of Medicine. The samples of normal endometrial tissues and endometrial carcinoma were collected after written informed consent was obtained from the patients.

Laser capture microdissection (LCM). Sections (thickness, $8-\mu \mathrm{m})$ were prepared from the frozen endometrial tissues. Approximately 5,000 cells were selected and isolated by laser capture using a light microscope (LMD 7000; Leica, Solms, Germany). Total RNA was extracted according to an RNA microisolation protocol previously described by Niino et al (13). A reverse transcription kit (Invitrogen, Carlsbad, CA, USA) was used for the synthesis of cDNA.

Cell culture and transfections. Human EC cell lines HEC-1B and RL95-2 were obtained from the Chinese Academy of Sciences Committee Type Culture Collection (Shanghai, China). The cells were cultured in Dulbecco's modified Eagle's medium/nutrient mixture F-12 (DMEM/F12) supplemented with $10 \%$ fetal bovine serum (FBS) and $1 \%$ penicillin/streptomycin (Gibco, Auckland, New Zealand) at $37^{\circ} \mathrm{C}$ in a humidified atmosphere containing $5 \% \mathrm{CO}_{2}$. HEC-1B and RL95-2 cells stably expressing ectopic FOXA1 or FOXA1-specific short hairpin RNA (shRNA) were generated as previously described (4). Where relevant, the AKT pathway agonist LY $294002(10 \mu \mathrm{M}$; Beyotime, Shanghai, China) was added to the cells $30 \mathrm{~min}$ prior to co-treatment with the shRNA plasmid.

Treatment of cells. Cells $\left(2 \times 10^{5}\right)$ were cultured in 6-well dishes. For hypoxia experiments, the cells were cultured in vitro in a hypoxic $\left(<0.1 \% \mathrm{O}_{2}\right)$ container system (BD Diagnostics, Sparks, MD, USA). Protein and RNA were collected immediately after cells were removed from the hypoxic container. For energy restriction experiments, the cells were cultured in serum-free medium for $72 \mathrm{~h}$ in a $5 \% \mathrm{CO}_{2}$ humidified incubator at $37^{\circ} \mathrm{C}$.

Senescence-associated $\beta$-gal staining (SABG). Cells $\left(1 \times 10^{5}\right)$ were seeded in 6 -well dishes ( $\geq$ triplicate wells). After treat- ment, cells were fixed with $0.2 \%$ glutaraldehyde $+2 \%$ formaldehyde in phosphate-buffered saline (PBS) at room temperature for $15 \mathrm{~min}$. After washing in PBS, the cells were stained with a solution containing $1 \mathrm{mg} / \mathrm{ml} \mathrm{X}$-gal (Beyotime) and incubated in a $\mathrm{CO}_{2}$-free incubator at $37^{\circ} \mathrm{C}$ for $16 \mathrm{~h}$. Green cells were counted and scanned with an Aperio ScanScope system (Aperio Technologies, Vista, CA, USA). The percentage of senescent cells was determined by counting cells in three randomly selected fields of images.

Immunofluorescence analysis. Cells cultured in 48-well plates were washed in PBS and fixed with $4 \%$ paraformaldehyde (Beyotime) for $15 \mathrm{~min}$. The cells were then incubated with PBS supplemented with $0.1 \%$ Triton $\mathrm{X}-100$ for $10 \mathrm{~min}$ at room temperature, blocked in 5\% normal goat serum for $30 \mathrm{~min}$ and washed in PBS. Nuclei were then stained with 4',6-diamidino-2-phenylindole (DAPI) (1:10,000; Beyotime) to visualize the SAHF. Three randomly selected fields were captured under a fluorescence microscope (Leica 126 DMI 3000B; Leica) and a total of 50 cells were counted in each sample to analyze the percentage of positively stained cells.

Cell proliferation assay. Cells $\left(3 \times 10^{3}\right.$ cells/well) were plated into 96-well plates. The cells were counted at $24 \mathrm{~h}$ intervals using a colorimetric assay with 3-(4,5-dimethylthiazol-2-yl)2,5-diphenyltetrazolium bromide (MTT; Sigma) performed as previously described (4). For the plate colony formation assay, 1,000 cells/well were seeded in 6 -well plates. Following the formation of clearly defined cell clones, the cells were fixed and stained with crystal violet and counted under a light microscope. Each experiment was repeated at least three times and assessed in triplicate.

Migration and invasion assays. Cell migration activity was evaluated using Boyden chambers containing polycarbonate filters (8- $\mu \mathrm{m}$ pore size; Millipore, Billerica, MA, USA). Cell invasive activity was assessed using a BD BioCoat Matrigel invasion chamber (BD Biosciences, Franklin Lakes, NJ, USA) following the manufacturer's recommendations. Cells were essentially treated as previously described (4). Each experiment was conducted, treated in triplicate and repeated at least three times.

Quantitative RT-PCR. Total RNA from the HEC-1B and RL95-2 cells was isolated using TRIzol (Invitrogen) and cDNA was prepared with the PrimeScript RT reagent kit (Takara, Otsu, Japan). PCR amplification of target genes was performed in a 50- $\mu 1$ reaction volume using single-stranded cDNA as the template. The primer sequences used in the present study are listed in Table I. The following protocol was used for PCR amplifications: 40 cycles of denaturation $\left(94^{\circ} \mathrm{C}\right)$ for $60 \mathrm{sec}$, annealing $\left(55^{\circ} \mathrm{C}\right)$ for $30 \mathrm{sec}$ and elongation $\left(72^{\circ} \mathrm{C}\right)$ for $30 \mathrm{sec}$ using SYBR Premix Ex Taq (Takara). All data were obtained in triplicate from three independent experiments and analyzed using the $2^{-\Delta \Delta C t}$ method.

Western blot analysis and antibodies. Western blot assays were performed as previously described (4). The following antibodies were used in the present study: anti-FOXA1 (1:1,000; Abcam, Cambridge, MA, USA), anti-p16 ${ }^{\mathrm{INK} 4 \mathrm{a}}(1: 2,000)$, anti- $\beta$-actin 
Table I. Primer sequences for real-time PCR analysis.

\begin{tabular}{lll}
\hline mRNA & & Primer sequence \\
\hline FOXA1 & F & 5'-AGGTGTGTATTCCAGACCCG-3' \\
& R & 5'-TTGACGGTTTGGTTTGTGTG-3' \\
p16 ${ }^{\text {INK4a }}$ & F & 5'-GAAGGTCCCTCAGACATCCCC-3' \\
& R & 5'-CCCTGTAGGACCTTCGGTGAC-3' \\
p144 ${ }^{\text {ARF }}$ & F & 5'-CCCTCGTGCTGATGCTACTG-3' \\
& R & 5'-ACCTGGTCTTCTAGGAAGCGG-3' \\
p15 ${ }^{\text {INK4b }}$ & F & 5'-CATTCCATGGATGCACAAAG-3' \\
& R & 5'-GCAATGGGAAGAAAAGCAAG-3' \\
p18 ${ }^{\text {INK4c }}$ & F & 5'-GGACCCAGGACTATCCCTTC-3' \\
& R & 5'-TTTAGGGTCCCTTGTTCACG-3' \\
p19 INK4d & F & 5'-CCAAGGGCAGAGCATTTAAG-3' \\
& R & 5'-AAGCAACGTGCACACTTCAG-3' \\
p53 & F & 5'-ACCACCATCCACTACAACTACAT-3' \\
& R & 5'-CACAAACACGCACCTCAAA-3' \\
PTEN & F & 5'-TCACCAACTGAAGTGGCTAA AGA-3' \\
& R & 5'-CTCCATTCCCCTAACCCGA-3' \\
ACTB & F & 5'-CAGCCATGTACGTTGCTATCCAGG-3' \\
& R & 5'-AGGTCCAGACGCAGGATGGCATG-3' \\
& &
\end{tabular}

F, forward; R, reverse; FOXA1, forkhead-box A1; PTEN, phosphate and tensin homology; ACTB, $\beta$-actin.

$(1: 75,00)$ (both from Epitomics, Burlingame, CA, USA), anti-AKT and anti-phospho-AKT (1:2,000; Cell Signaling Technology, Danvers, MA, USA).

Statistical analysis. Each experiment was repeated for at least three independent occasions. All statistical analysis was performed with the Statistical Package for the Social Science (SPSS) software version 17.0 (SPSS, Inc., Chicago, IL, USA). Data represent the mean \pm standard deviation (SD). Data were compared using two-tailed Student's t-test or Mann-Whitney U test for multiple comparisons. Differences with a probability of $\mathrm{P}<0.05$ were regarded as statistically significant.

\section{Results}

FOXAl overexpression is associated with good prognosis in $E C$. In our previous study, we found that FOXA1 was significantly downregulated in EC tissues compared to that noted in normal endometrium (4). To further assess the role of FOXA1 in EC, we compared FOXA1 expression with prognostic factors in normal endometrium and EC tissues using initial reverse transcription-quantitative PCR (RT-qPCR) and IHC analyses. RT-qPCR analysis of normal endometrium and EC cells captured by LCM revealed that FOXA1 mRNA levels were higher in the normal endometrium than levels in the EC tissues $(\mathrm{P}<0.001$; Fig. 1A), and indicated that there were significant differences in FOXA1 expression among tumor grades $(\mathrm{P}<0.001$; Fig. 1B). Furthermore, the IHC results showed that FOXA1 was negatively associated with the depth of myometrial invasion $(\mathrm{P}<0.001$; Fig. 1C) and lymph node metastasis of EC $(\mathrm{P}<0.01$; Fig. 1D), which is consistent with the results previously described by Abe et al (14). The pattern of FOXA1 expression was correlated with ER $\alpha$ expression $(\mathrm{P}<0.001$; Fig. 1E), but showed no significant correlation with the expression of PR and p53 (P>0.05; Fig. 1F and G). These data suggest that FOXA1 expression is correlated with EC and the prognostic ability of FOXA1 in low-risk EC may be useful in making clinical treatment decisions.

FOXA1 is upregulated in senescent EC cells. Previously, we demonstrated that FOXA1 suppresses the progression of EC and evidence is emerging that inhibition of FOXA1 is essential for EC cell growth and survival. We hypothesized that FOXA1 contributes to the activation of tumor suppressor networks in senescence. EC HEC-1B and RL95-2 cell lines were subjected to conditions of hypoxia or energy restriction (hunger) to promote cell senescence (7). Cells were then stained for $\beta$-galactosidase activity, a widely used biomarker for senescent cells $(\mathrm{P}<0.01$; Fig. 2A) $(\mathrm{P}<0.001$; Fig. 2B). Compared to the untreated group, robust induction of FOXA1 was observed in the senescent EC cells at both the mRNA and protein levels, and was correlated with increased $16^{\mathrm{INK} 4 \mathrm{a}}$ expression $(\mathrm{P}<0.05$; Fig. 2C) $(\mathrm{P}<0.05$; Fig. 2D).

FOXA1 triggers multiple steps of cellular senescence in EC cells and activates p16 ${ }^{I N K 4 a}$ expression. Several lines of evidence have linked FOXA1 with cell senescence. To further characterize the functional role of FOXA1 in EC cells, we restored FOXA1 expression in HEC-1B cells (Fig. 3A). MTT and plate colony formation assays revealed that HEC-1B cells transiently transfected with a FOXA1 expression plasmid showed significant growth inhibition and limited colony formation compared with the cells transfected with the negative control vector $(\mathrm{P}<0.001$; Fig. $3 \mathrm{~A})$. Furthermore, restoring FOXA1 expression induced morphological features of senescence, including accumulation of granular cytoplasmic inclusions and elevated $\beta$-galactosidase activity.

As a comparison with the effects of FOXA1 overexpression, we transiently transfected RL95-2 cells with a vector encoding a short hairpin RNA (shRNA) against FOXA1 or its corresponding negative control (Fig. 3B). FOXA1 depletion promoted a statistically significant induction of cell proliferation and the cells transfected with shFOXA1 formed more colonies than those transfected with the control vector $(\mathrm{P}<0.01$; Fig. 3B). All of these results suggest that FOXA1 triggers multiple steps of cellular senescence in EC cells.

There are several senescence-associated genes and key cell cycle regulators in senescence networks. We, therefore, investigated the association of the restoration of FOXA1 expression in HEC-1B cells with these key genes. Expression of p16 $6^{\mathrm{INK} 4 \mathrm{a}}$ and $\mathrm{p} 18^{\mathrm{INK} 4 \mathrm{c}}$ was increased $(\mathrm{P}<0.05$; Fig. $3 \mathrm{C})$ while expression of the other genes such as phosphate and tensin homology (PTEN), p53 or p27 ${ }^{\mathrm{kip} 1}$ showed no marked changes. These observations provided further evidence of the association of FOXA1 with senescence in EC.

FOXA1 promotes senescence in EC cells via the AKT pathway. A recent study showed that inhibition of AKT results in increased cellular senescence in uterine leiomyoma cells, 
A

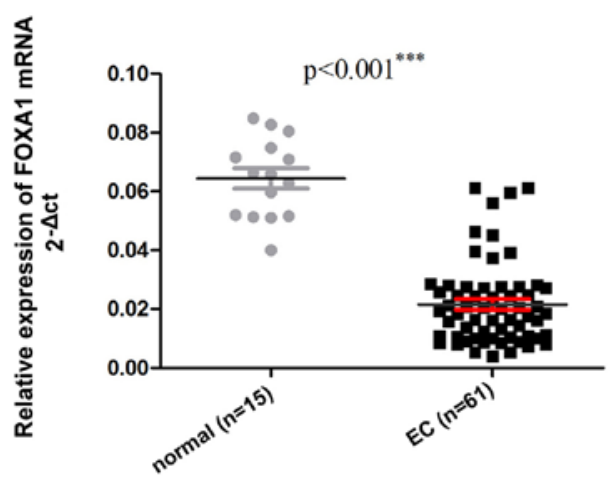

C

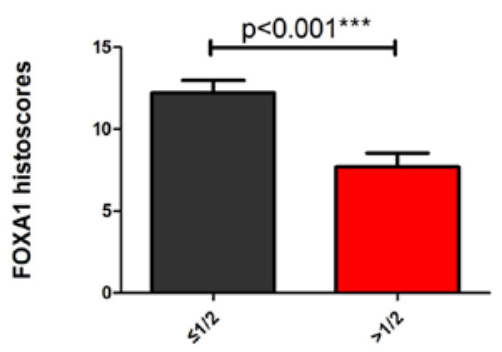

Myometrial invasion
B

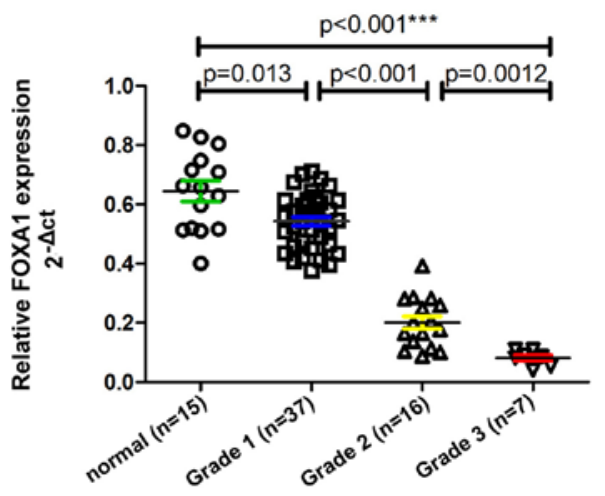

D

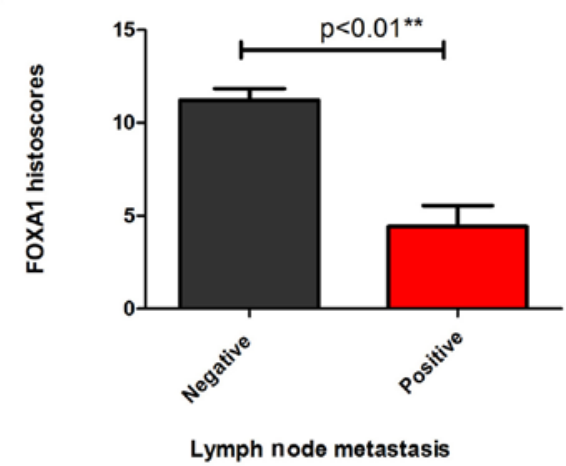

$\mathrm{E}$

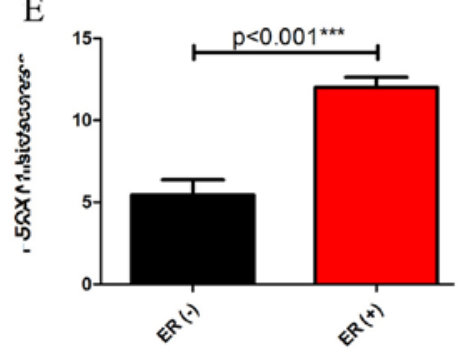

F

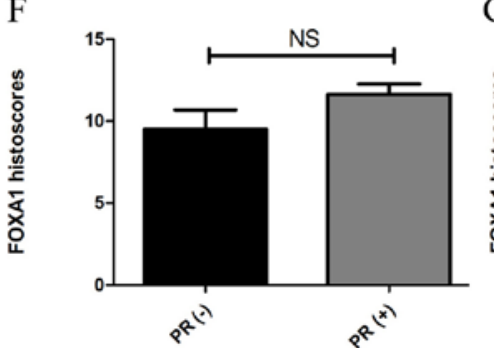

G

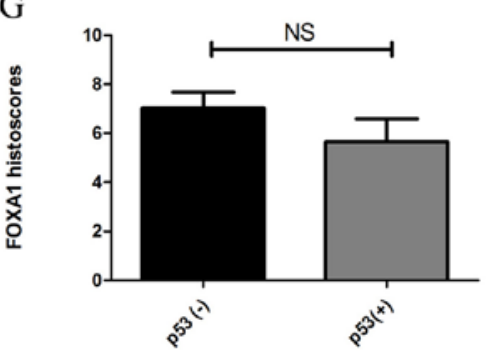

Figure 1. FOXA1 overexpression in endometrial tissues and cells is associated with a good prognosis. (A) Quantitative reverse transcription-polymerase chain reaction (qRT-PCR) of FOXA1 in endometrial cancer (EC) specimens ( $n=61)$ and normal tissues $(n=15)$. FOXA1 expression was normalized against $\beta$-actin. (B) FOXA1 expression was significantly decreased in grades 2 and 3 compared with grade 1 disease. (C) The depth of myometrial invasion and (D) lymph node metastasis of EC was negatively associated with FOXA1 histoscores in the immunohistochemical analysis; ${ }^{* *} \mathrm{P}<0.01,{ }^{* * *} \mathrm{P}<0.001$. $(\mathrm{E}) \mathrm{FOXA} 1 \mathrm{was}$ expressed at much higher levels in the ER-positive ECs than in the ER-negative ECs, but showed no significant correlation with $(\mathrm{F}) \mathrm{PR}$ and $(\mathrm{G}) \mathrm{p} 53$; NS, $\mathrm{P}>0.05$. ${ }^{* *} \mathrm{P}<0.01$ *** $\mathrm{P}<0.001$.

accompanied by increased levels of several senescence-associated genes (including p16, p53 and p21) (15). These findings raised the possibility that FOXA1-induced senescence is associated with the AKT pathway in EC. To test this hypothesis, HEC-1B cells were treated with different concentrations of LY 294002, a selective PI3K inhibitor, which inhibits cell proliferation and induces apoptosis $(16,17)$. Western blot analysis of the protein levels of $\mathrm{p}(\mathrm{Ser} 473)$-AKT and AKT revealed almost complete inhibition of $\mathrm{p}$-AKT expression in cells treated with LY 294002 at 1, 10 and $20 \mu \mathrm{M}$, with optimal inhibition achieved at $10 \mu \mathrm{M}(\mathrm{P}<0.001$; Fig. 4A). SABG and SAHF assays were performed to investigate whether inhibition of the AKT pathway induces senescence in EC. Treatment with LY $294002(10 \mu \mathrm{M})$ resulted in a significant increase in $\beta$-galactosidase stained cells $(\mathrm{P}<0.001$; Fig. 4B). Furthermore, $\sim 40 \%$ of cells exhibited SAHF when treated with LY 294002 compared to $15 \%$ in the negative control group $(\mathrm{P}<0.001$; Fig. 4C). Additionally, following treatment with LY 294002, expression of the senescence-associated genes $\mathrm{p}^{\mathrm{INK}} \mathrm{I}^{\mathrm{INa}}$ and p2 $7^{\mathrm{kip} 1}$ was markedly increased, while PTEN gene expression was decreased $(\mathrm{P}<0.05$; Fig. 4D). All of these results demonstrated that inhibition of AKT in EC cells induced senescence.

Next, we examined the relationship between FOXA1 and the AKT pathway. We found that in HEC-1B cells, FOXA1 overexpression abolished the p-AKT expression at the protein level (Fig. 4E) and in RL95-2 cells, decreased FOXA1 expression was correlated with increased levels of p-AKT (Fig. 4E), with no obvious changes in AKT levels. All of these results indicated a reverse role for FOXA1 in mediating the AKT pathway in EC. 
A
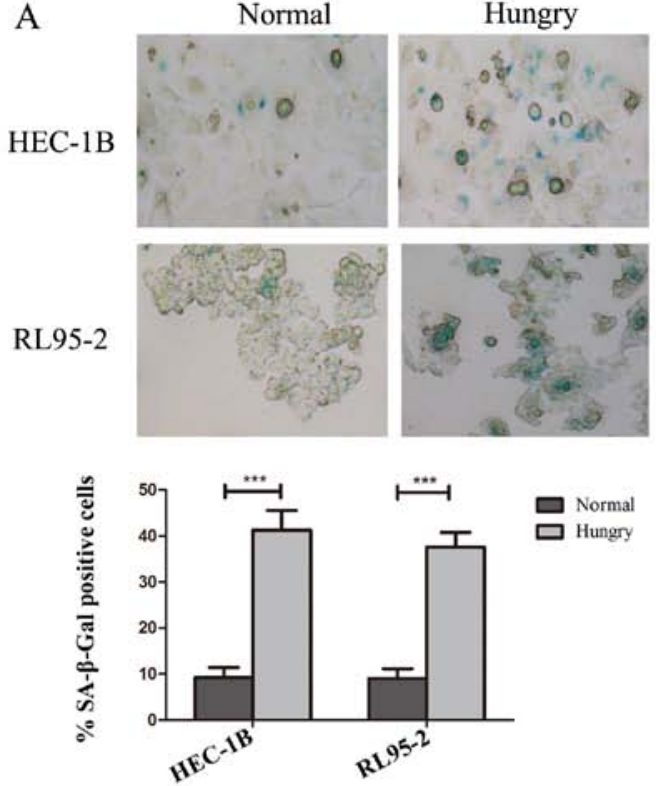

$\mathrm{C}$
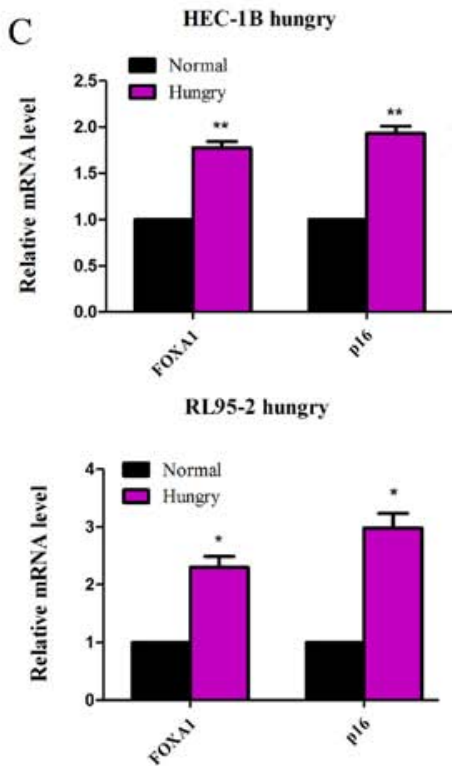

B

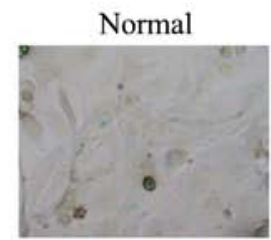

RL95-2
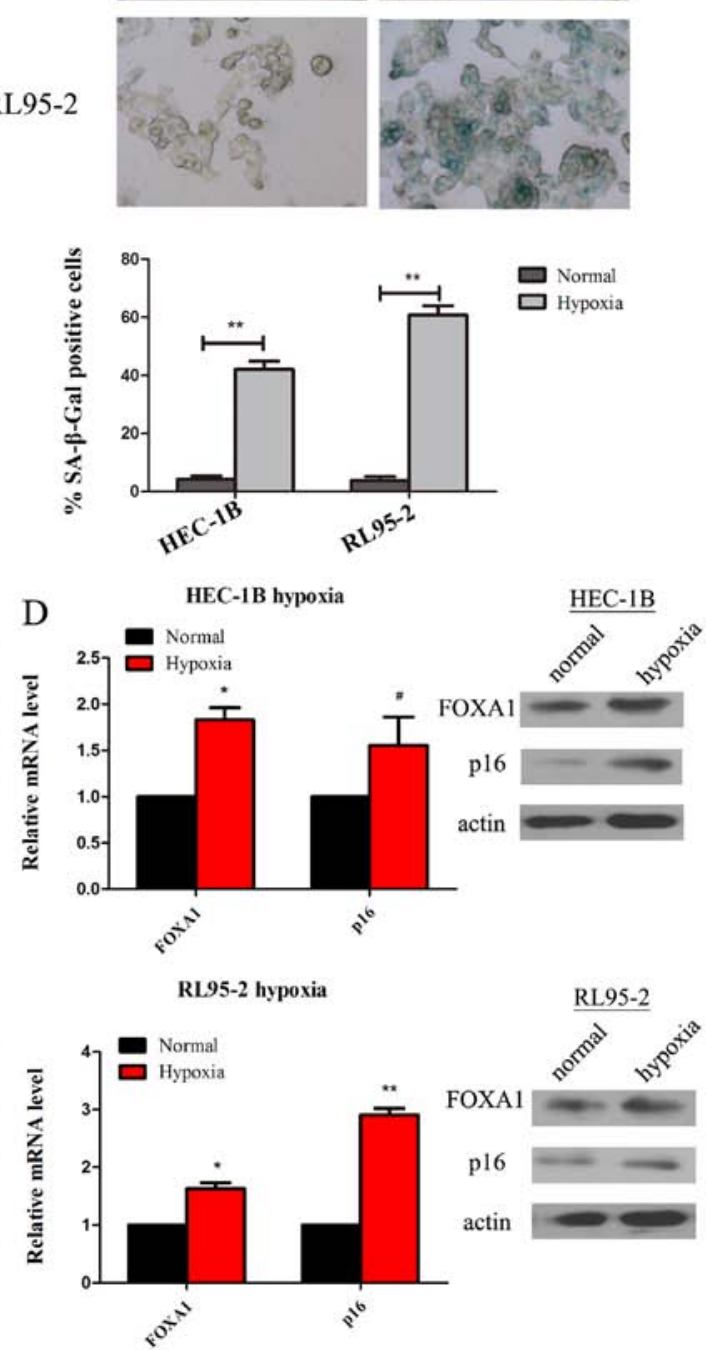

Figure 2. FOXA1 is upregulated in senescent endometrial cancer (EC) cells. (A) EC HEC-1B and (B) RL95-2 cell lines were subjected to conditions of hypoxia or energy restriction (hungry) to promote cell senescence. Representative images showing cells stained for $\beta$-galactosidase activity and further quantification of the results by densitometry in triplicate experiments. (C) Increased mRNA and (D) protein levels of FOXA1 and p16 ${ }^{\text {INK4a }}$ in senescent EC cells. Data represent the mean \pm standard deviation (SD). $\beta$-actin was used as a loading control; ${ }^{*} \mathrm{P}<0.05,{ }^{* *} \mathrm{P}<0.01,{ }^{* * *} \mathrm{P}<0.001$.

\section{Discussion}

Endometrial cancer (EC) is the most prevalent malignancy in women, although the mechanism of EC tumorigenesis and metastasis remain to be clarified. In our previous study, we found that FOXA1 suppressed the progression of estrogen receptor (ER)-positive EC, which was consistent with other studies $(14,18)$. We also found that FOXA1 promoted cell proliferation via the androgen receptor (AR) and activated Notch pathway in ER-negative, AR-positive EC (19). Thus, FOXA1 is a bifunctional cancer-associated gene, which is oncogenic or tumor suppressive in a context-dependent manner. However, in the present study, our data support the hypothesis that FOXA1 is associated with senescence in EC, playing a role in addition to its function as a pioneer factor.
Our findings showed that FOXA1 is downregulated in EC compared to normal endometrium and low-FOXA1 expression is significantly associated with markers of a poorer outcome as well as poor survival. The positive correlation between FOXA1 and $16^{\mathrm{INK} 4 \mathrm{a}}$ was observed in EC tissues, which is consistent with the recent studies that positive regulation of $\mathrm{p} 16^{\mathrm{INK} 4 \mathrm{a}}$ by FOXA1 counteracts its tumorigenic repression of by EZH2 in cancers (20). This indicated that FOXA1 may have a role in EC that is not linked to ER $\alpha$, and that the function of FOXA1 could be organ specific. In accordance with our results, recent findings in EC have revealed that gene expression related to FOXA1 levels do not overlap with the pattern of ER $\alpha$ expression (18).

In the present study, we initially found that FOXA1 was upregulated in senescent EC cell lines, which was correlated 
A
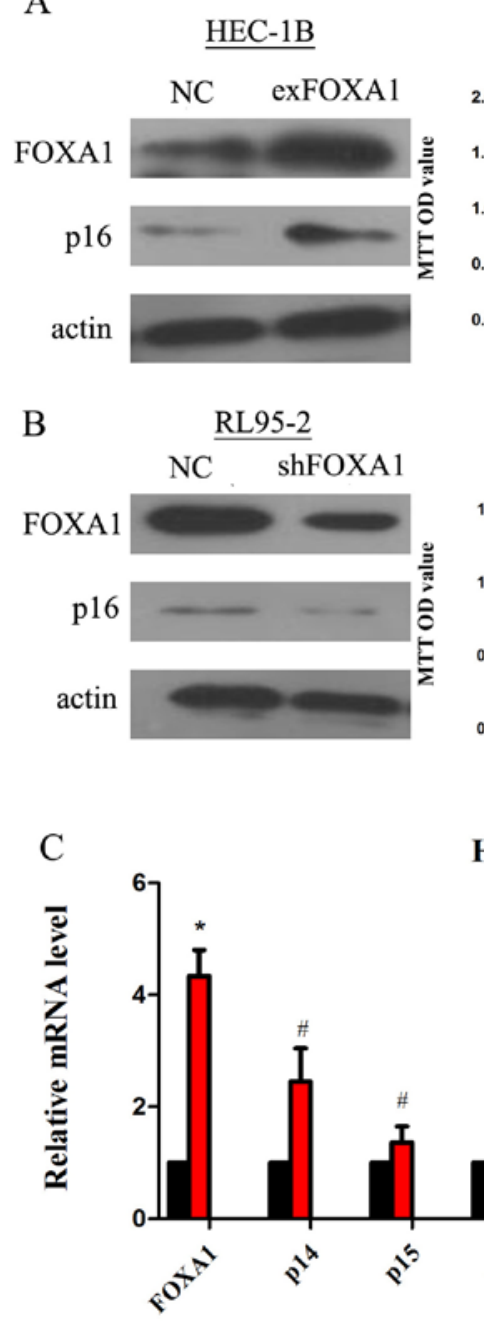

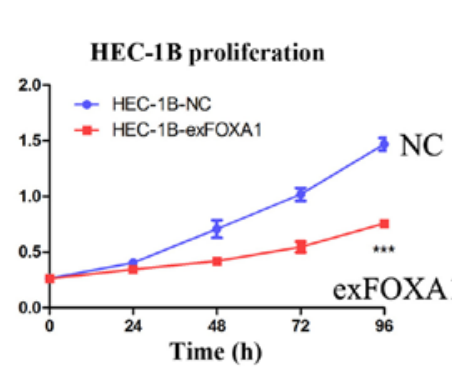

RL95-2 proliferation

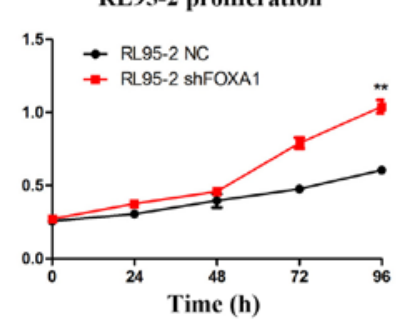

HEC-1B
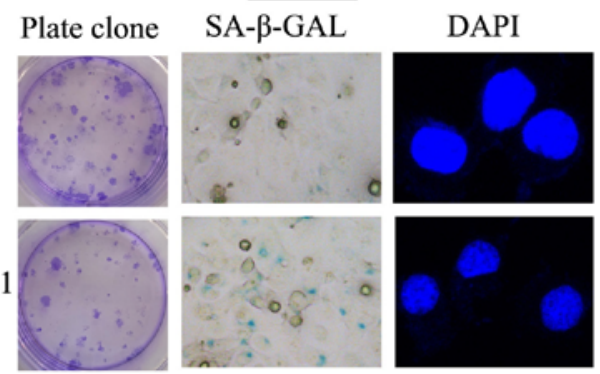

HEC-1B eXFOXA1
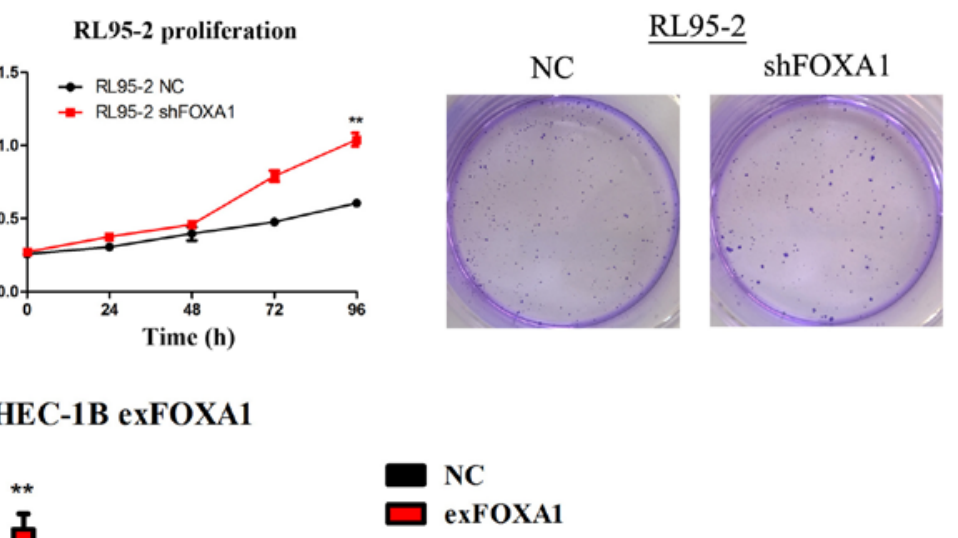

Figure 3. FOXA1 triggers multiple steps of cellular senescence in EC cells and activates p16 ${ }^{\mathrm{INK} 4 \mathrm{a}}$ expression. (A) Ectopic expression of FOXA1 caused premature senescence. HEC-1B cells were transfected with a plasmid expressing FOXA1 or a control vector. Expression of FOXA1 (determined by western blotting) was correlated with increased $16^{\mathrm{INK} 4 \mathrm{a}}$ (first panel, left). MTT and plate colony formation assays revealed that HEC-1B cells transiently transfected with the FOXA1 expression plasmid showed significant growth inhibition and limited colony formation compared with those transfected with the negative control vectors (second and third panels). Data represent the mean \pm standard deviation (SD); ${ }^{* * *} \mathrm{P}<0.001$. Representative images of indicated cells stained for $\beta$-galactosidase and senescence-associated heterochromatin foci (SAHF) are shown (first and second panel, right). (B) Depletion of FOXA1 impaired p16 ${ }^{\text {INK4a }}$ activation and senescence progression. RL95-2 cells were transfected with a vector encoding a short hairpin RNA (shRNA) against FOXA1 or its corresponding negative control. Protein expression of FOXA1 and p16 ${ }^{\mathrm{INK} 4 \mathrm{a}}$ were assessed in RL95-2 cells. MTT and plate colony formation assays revealed that FOXA1 depletion promoted a statistically significant induction of cell proliferation and more colony formation compared with those transfected with the negative control vector; ${ }^{* *} \mathrm{P}<0.01$. (C) FOXA1 overexpression was accompanied by increased mRNA expression of several senescence-associated genes. $\beta$-actin was used as a loading control; ${ }^{*} \mathrm{P}<0.05,{ }^{* *} \mathrm{P}<0.01,{ }^{\#} \mathrm{P}>0.05$.

with increased p16 ${ }^{\text {INK4a }}$ expression. FOXA1 can mimic linker histones and bind directly to compacted chromatin (21), functioning as a pivotal regulator of chromatin remodeling of the $\mathrm{p} 16^{\mathrm{INK} 4 \mathrm{a}}$ promoter, which is the key senescence-associated gene $(10,20)$. To understand the interplay of chromatin, senescence and EC, further studies are required to elucidate the functional and causal roles of senescence-associated chromatin features in preventing tumor phenotype and to delineate the underlying mechanisms. Our data support the hypothesis that FOXA1 is a transcription factor that is induced during senescence in EC. Li et al showed that FOXA1 was significantly upregulated in senescent human 2BS diploid fibroblast cells (10); therefore, we proposed that FOXA1 is also associated with senescence in EC, the functional role of FOXA1 in tumor progression should not be restricted to its 'pioneering' role associated with hormone receptors.
Since cancer and senescence may share certain molecular processes (22), it is plausible that FOXA1 prevented EC by acting on the senescence process. In the present study, further phenotypic and biochemical investigations showed that inhibition of FOXA1 resulted in decreased growth of EC cells and promoted cell senescence. Cell senescence can be defined as a stable arrest of the cell cycle coupled to stereotypical phenotypic change (5). On this basis, we proposed that the accumulation of senescent cells in EC tissue suppresses the progression of cancer. In accordance with previous reports that $\mathrm{p} 16^{\mathrm{INK} 4 \mathrm{a}}$ expression is upregulated in endometrial polyps compared to endometrial hyperplasia due to the p16-induced cellr senescence (23), our functional investigations indicated that $16^{\mathrm{INK} 4 \mathrm{a}}$ acts downstream of FOXA1 to regulate carcinogenesis. Recent studies also suggest that $\mathrm{p} 16^{\mathrm{INK} 4 \mathrm{a}}$ is one of the most differentially expressed genes associated with FOXA1 
A
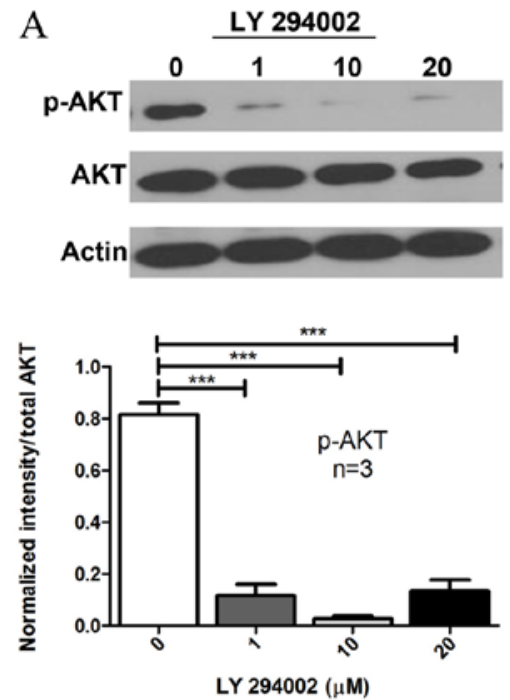

B

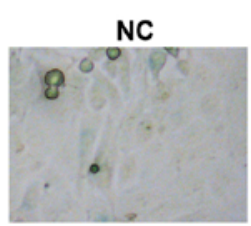

C

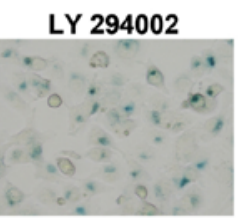

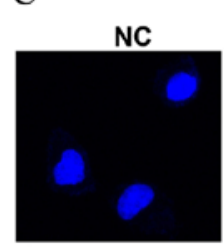
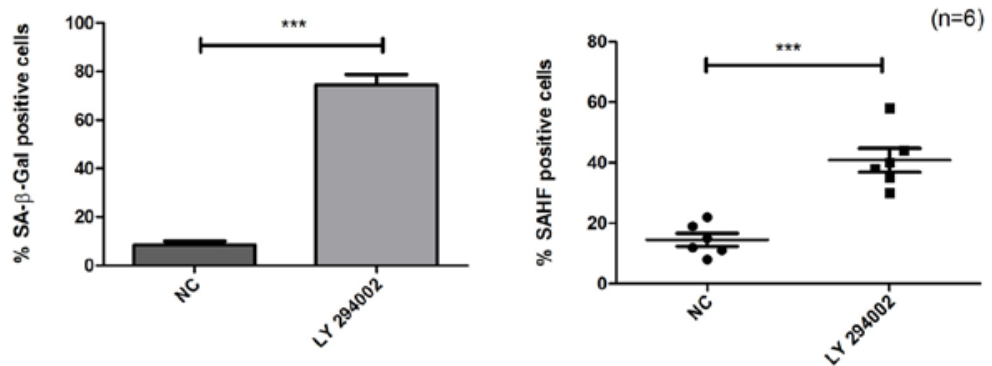

$(n=6)$

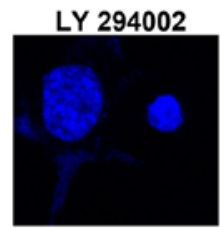

E

E HEC-1B

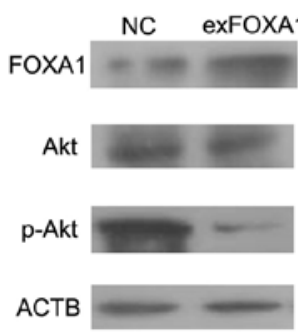

RL95-2

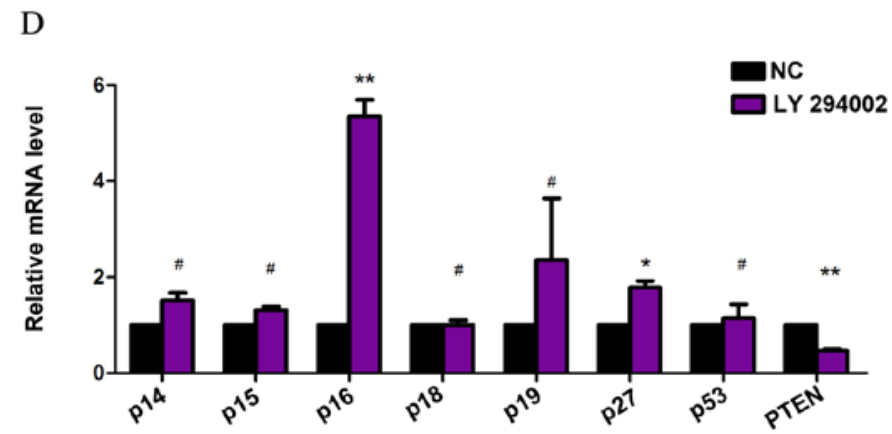

Figure 4. FOXA1 promotes senescence in EC cells via the AKT pathway. (A) Following treatment of HEC-1B cells with different concentrations of LY 294002, the protein levels of $\mathrm{p}\left(\right.$ Ser473)-AKT and AKT were evaluated by western blotting and further quantified by densitometry in triplicate experiments; ${ }^{* * *} \mathrm{P}<0.001$. (B) Representative images of indicated cells stained for $\beta$-galactosidase and (C) senescence-associated heterochromatin foci (SAHF) are shown. More senescent EC cells were observed following treatment with LY 294002; ${ }^{* * *} \mathrm{P}<0.001$. (D) LY 294002 inhibition of the AKT pathway was accompanied by increased levels of p16 ${ }^{\mathrm{INK} 4 \mathrm{a}}$ and $\mathrm{p} 27^{\mathrm{kip} 1} \mathrm{mRNA}$ and decreased levels of PTEN mRNA; ${ }^{*} \mathrm{P}<0.05,{ }^{* *} \mathrm{P}<0.01,{ }^{\#} \mathrm{P}>0.05$. (E) Expression of AKT and $\mathrm{p}-\mathrm{AKT}$ proteins was assessed in FOXA1-overexpressing HEC-1B cells. The elevation of FOXA1 expression was accompanied by increased p-AKT protein levels. In RL95-2 cells, decreased FOXA1 expression was correlated with increased p-AKT levels.

protein expression in metastatic EC lesions (18). Thus, we speculated that cell senescence is the barrier to EC, and is regulated by FOXA1-induced $\mathrm{p} 16^{\mathrm{INK} 4 \mathrm{a}}$ expression.

It has been shown in uterine leiomyomas that AKT inhibition results in a transient regulation of specific mechanisms that ultimately drive cells into cellular senescence or death (15). In the present study, we have demonstrated that upregulation of FOXA1 blocks AKT pathway activation and is accompanied by changes in the expression of several key senescence-associated genes (p16, p27 and PTEN) in EC cells. Although our knowledge of specific mechanism of cell senescence in EC reported is limited, AKT has been shown to protect against RAS-induced senescence in other cell types (24), and several classical transcription factors related to senescence have been identified, including p16, p21 and p53 (25-27). Based on our findings, we suggest that FOXA1 promotes cell senescence in EC by interaction with p16 ${ }^{\mathrm{INK} 4 \mathrm{a}}$, possibly via the AKT pathway, which may be a newly identified regulatory mechanism of cell senescence in EC.

Despite our understanding of FOXA1-mediated p16 ${ }^{\mathrm{INK} 4 \mathrm{a}}$ activation in senescence, the deregulation of the FOXA1/p16 ${ }^{\mathrm{INK} 4 \mathrm{a}}$ axis in EC cancer biology remains to be clarified. FOXA1 is downregulated in numerous cancer tissues compared to their normal counterparts (28-30) and a positive correlation between
FOXA1 and p16 ${ }^{\mathrm{INK} 4 \mathrm{a}}$ is observed in breast cancers with lower EZH2 (epigenetic repressor for p16 ${ }^{\mathrm{INK} 4 \mathrm{a}}$ ) (20). However, further studies are required to determine whether the downregulation of FOXA1 expression is associated with epigenetic inactivation. BRCA1 has been proposed to maintain FOXA1 expression in breast cancer by suppressing FOXA1 gene methylation (31), although little is known regarding the methylation status of the FOXA1 promoter in EC. This information may further our understanding of the mechanisms of EC.

In summary, the results of the present study indicate that FOXA1 expression may be a characteristic of EC and constitute a useful prognostic marker. FOXA1 is upregulated in senescent EC cells and mediates $\mathrm{p} 16^{\mathrm{INK} 4 \mathrm{a}}$ activation to promote cell senescence.

\section{Acknowledgements}

The present study was supported by the National Natural Science Foundation of China (no. 81272885), the Foundation Project of Shanghai Science and Technology Commission (no. 15ZR1433400 and no. 16ZR1427100) and the Young Talents Training Programs Foundation of Tongji University (no. 1400811). 


\section{References}

1. Siegel RL, Miller KD and Jemal A: Cancer statistics, 2015. CA Cancer J Clin 65: 5-29, 2015.

2. Yuan X, Wang LU, Xue J, Li LI and Zhang J: Endocrine MPA enhances the effects of TAC chemotherapy on improvement of prognosis and increase in long-term survival rates for patients with endometrial cancer. Oncol Lett 10: 1902-1906, 2015.

3. Bernardo GM and Keri RA: FOXA1: A transcription factor with parallel functions in development and cancer. Biosci Rep 32: 113-130, 2012.

4. Wang J, Bao W, Qiu M, Liao Y, Che Q, Yang T, He X, Qiu H and Wan X: Forkhead-box A1 suppresses the progression of endometrial cancer via crosstalk with estrogen receptor $\alpha$. Oncol Rep 31: 1225-1234, 2014.

5. Kuilman T, Michaloglou C, Mooi WJ and Peeper DS: The essence of senescence. Genes Dev 24: 2463-2479, 2010.

6. Falandry C, Bonnefoy M, Freyer G and Gilson E: Biology of cancer and aging: A complex association with cellular senescence. J Clin Oncol 32: 2604-2610, 2014.

7. López-Otín C, Blasco MA, Partridge L, Serrano M and Kroemer G: The hallmarks of aging. Cell 153: 1194-1217, 2013.

8. Kool J, Uren AG, Martins CP, Sie D, de Ridder J, Turner G van Uitert M, Matentzoglu K, Lagcher W, Krimpenfort P, et al: Insertional mutagenesis in mice deficient for $p 15^{\operatorname{Ink} 4 b}$, p16 $6^{\operatorname{Ink} 4 a}$, $p 21^{C i p l}$, and $p 27^{K i p l}$ reveals cancer gene interactions and correlations with tumor phenotypes. Cancer Res 70: 520-531, 2010.

9. McLaughlin-Drubin ME, Park D and Munger K: Tumor suppressor $16^{\mathrm{INK} 4 \mathrm{~A}}$ is necessary for survival of cervical carcinoma cell lines. Proc Natl Acad Sci USA 110: 16175-16180, 2013.

10. Li Q, Zhang Y, Fu J, Han L, Xue L, Lv C, Wang P, Li G and Tong T: FOXA 1 mediates p16 $6^{\mathrm{INK} 4 \mathrm{a}}$ activation during cellular senescence. EMBO J 32: 858-873, 2013.

11. Hanahan D and Weinberg RA: Hallmarks of cancer: The next generation. Cell 144: 646-674, 2011.

12. Collado M, Blasco MA and Serrano M: Cellular senescence in cancer and aging. Cell 130: 223-233, 2007.

13. Niino YS, Irie T, Takaishi M, Hosono T, Huh N, Tachikawa T and Kuroki T: PKCtheta II, a new isoform of protein kinase $\mathrm{C}$ specifically expressed in the seminiferous tubules of mouse testis. J Biol Chem 276: 36711-36717, 2001

14. Abe Y, Ijichi N, Ikeda K, Kayano H, Horie-Inoue K, Takeda S and Inoue S: Forkhead box transcription factor, forkhead box A1, shows negative association with lymph node status in endometrial cancer, and represses cell proliferation and migration of endometrial cancer cells. Cancer Sci 103: 806-812, 2012.

15. Xu X, Lu Z, Qiang W, Vidimar V, Kong B, Kim JJ and Wei JJ: Inactivation of AKT induces cellular senescence in uterine leiomyoma. Endocrinology 155: 1510-1519, 2014.

16. Chaussade C, Rewcastle GW, Kendall JD, Denny WA, Cho K, Grønning LM, Chong ML, Anagnostou SH, Jackson SP, Daniele N, et al: Evidence for functional redundancy of class IA PI3K isoforms in insulin signalling. Biochem J 404: 449-458, 2007.

17. Semba S, Itoh N, Ito M, Harada M and Yamakawa M: The in vitro and in vivo effects of 2-(4-morpholinyl)-8-phenyl-chromone (LY294002), a specific inhibitor of phosphatidylinositol 3'-kinase, in human colon cancer cells. Clin Cancer Res 8: 1957-1963, 2002.
18. Tangen IL, Krakstad C, Halle MK, Werner HM, Oyan AM, Kusonmano K, Petersen K, Kalland KH, Akslen LA, Trovik J, et al: Switch in FOXA1 status associates with endometrial cancer progression. PLoS One 9: e98069, 2014.

19. Qiu M, Bao W, Wang J, Yang T, He X, Liao Y and Wan X: FOXA1 promotes tumor cell proliferation through AR involving the Notch pathway in endometrial cancer. BMC Cancer 14: 78, 2014.

20. Zhang $\mathrm{Y}$ and Tong T: FOXA1 antagonizes EZH2-mediated CDKN2A repression in carcinogenesis. Biochem Biophys Res Commun 453: 172-178, 2014.

21. Hirai H, Tani $\mathrm{T}$ and Kikyo N: Structure and functions of powerful transactivators: VP16, MyoD and FoxA. Int J Dev Biol 54: 1589-1596, 2010

22. Serrano M: Unraveling the links between cancer and aging. Carcinogenesis 37: 107, 2016

23. Moritani S, Ichihara S, Hasegawa M, Iwakoshi A, Murakami S, Sato T, Okamoto T, Mori Y, Kuhara $\mathrm{H}$ and Silverberg SG: Stromal p16 expression differentiates endometrial polyp from endometrial hyperplasia. Virchows Arch 461: 141-148, 2012.

24. Kennedy AL, Morton JP, Manoharan I, Nelson DM, Jamieson NB, Pawlikowski JS, McBryan T, Doyle B, McKay C, Oien KA, et al: Activation of the PIK3CA/AKT pathway suppresses senescence induced by an activated RAS oncogene to promote tumorigenesis. Mol Cell 42: 36-49, 2011.

25. Goswami A, Shah BA, Kumar A, Rizvi MA, Kumar S, Bhushan S, Malik FA, Batra N, Joshi A and Singh J: Antiproliferative potential of a novel parthenin analog $\mathrm{P} 16$ as evident by apoptosis accompanied by down-regulation of PI3K/AKT and ERK pathways in human acute lymphoblastic leukemia MOLT-4 cells. Chem Biol Interact 222C: 60-67, 2014.

26. Kipkeew F, Kirsch M, Klein D, Wuelling M, Winterhager E and Gellhaus A: CCN1 (CYR61) and CCN3 (NOV) signaling drives human trophoblast cells into senescence and stimulates migration properties. Cell Adh Migr 10: 163-178, 2016.

27. Wu J, Chen C, Hu X, Cai X, Guan Y, Hu H, Wang Q, Chen X, Cai B and Jing X: Suppressing cyclooxygenase-2 prevents nonalcoholic steatohepatitis and inhibits apoptosis of hepatocytes that are involved in the Akt/p53 signal pathway. Biochem Biophys Res Commun 469: 1034-1040, 2016.

28. Ren H, Zhang P, Tang Y, Wu M and Zhang W: Forkhead box protein A1 is a prognostic predictor and promotes tumor growth of gastric cancer. Onco Targets Ther 8: 3029-3039, 2015.

29. Song Y, Washington MK and Crawford HC: Loss of FOXA1/2 is essential for the epithelial-to-mesenchymal transition in pancreatic cancer. Cancer Res 70: 2115-2125, 2010.

30. Tachi K, Shiraishi A, Bando H, Yamashita T, Tsuboi I, Kato T, Hara $\mathrm{H}$ and Ohneda O: FOXA1 expression affects the proliferation activity of luminal breast cancer stem cell populations. Cancer Sci 107: 281-289, 2016.

31. Gong C, Fujino K, Monteiro LJ, Gomes AR, Drost R, Davidson-Smith H, Takeda S, Khoo US, Jonkers J, Sproul D, et al: FOXA1 repression is associated with loss of BRCA1 and increased promoter methylation and chromatin silencing in breast cancer. Oncogene 34: 5012-5024, 2015. 